\title{
Rancang Bangun Pendinginan Suhu Pada Jaket Menggunakan Mikrokontroler Berbasis Android
}

\author{
Yaumil Irana ${ }^{1}$, Waluyo,Ir.,MT ${ }^{2}$, M.Nanak Zakaria,ST,MT ${ }^{3}$ \\ 1,2,3 Program Studi Jaringan Telekomunikasi Digital, \\ Jurusan Teknik Elektro, Politeknik Negeri Malang, Indonesia \\ 1.iranayaumil@gmail.com, ${ }^{2}$ waluyo@polinema.ac.id, ${ }^{3}$ nanak_zach@polinema.ac.id
}

\begin{abstract}
Physical exercise is an activity carried out to maintain a healthy body condition. Health is the most important part of all activities carried out by humans by paying attention to vital signs such as body temperature, heart rate, and others on a regular basis. Regular physical exercise for a long time, which is about 30 minutes, can cause changes in bodily functions. The acute effect of excessive physical exercise results in an increase in heart rate and body temperature. This study is designed to control and monitor body temperature as well as other vital signs of health during exercise, and to avoid excessive physical exercise. Research that has been conducted previously obtained the results of values before exercise for body temperature using infrared and ds18b20 which have a range between $34.550 \mathrm{C}-36.090 \mathrm{C}$ and $35.060 \mathrm{C}-36.190 \mathrm{C}$, values for skin moisture range from $47 \%$ and heart rates between $94 \mathrm{Bpm}-$ $118 \mathrm{Bpm}$. Meanwhile, during the exercise, the body temperature is between 36.380C - 36.810C, skin moisture between $47 \%-15 \%$, and a heart rate between $105 \mathrm{Bpm}-95 \mathrm{Bpm}$ with a value of delay between $0.034897000 \mathrm{~s}-0.037563000 \mathrm{~s}$ during the live streaming. Based on this research, it can be concluded that the fan can turn on automatically and successfully reduce the user's body temperature gradually with a temperature range between $35,000 \mathrm{C}-36.80 \mathrm{C}$.
\end{abstract}

Keywords - Body temperature, heart rate, android, thermal infrared non-contact

Abstrak - Paparan tekanan panas dapat terjadi pada masyarakat yang sedang melakukan latihan fisik berlebih sehingga menimbulkan gejala tekanan panas seperti peningkatan suhu tubuh dan denyut nadi. Latihan fisik dalam waktu kurang lebih selama 30 menit dapat menyebabkan perubahan terhadap fungsi tubuh. Efek akut dari latihan fisik yang berlebihan mengakibatkan peningkatan terhadap frekuensi denyut jantung, dan suhu tubuh. Tujuan dari skripsi ini adalah membuat alat yang diimplementasikan dalam jaket untuk mengkontrol dan memonitoring suhu tubuh, kelembaban kulit, dan denyut jantung secara bersamaan pada saat berolahraga. Alat ini dirancang dengan sistem kontrol dan monitoring pada komponen yang sudah terpasang, kemudian data yang diperoleh disimpan dalam database dan dikirimkan secara wireless melalui NodeMCU nantinya dapat ditampilkan dalam aplikasi android. Penelitian yang sudah dilakukan, diperoleh hasil nilai sebelum olahraga untuk suhu tubuh menggunakan infrared dan ds18b20 memiliki rentang antara $34.55^{\circ} \mathrm{C}-36.09^{\circ} \mathrm{C}$ dan $35.06^{\circ} \mathrm{C}-36.19^{\circ} \mathrm{C}$, nilai pada kelembaban kulit berkisar $47 \%$ dan denyut jantung antara $94 \mathrm{Bpm}-118 \mathrm{Bpm}$. Sedangkan pada saat olahraga berlangsung didapatkan suhu tubuh antara $36.38^{\circ} \mathrm{C}-36.81^{\circ} \mathrm{C}$, kelemaban kulit antara $47 \%-15 \%$, dan denyut jantung antara $105 \mathrm{Bpm}-95 \mathrm{Bpm}$ dengan nilai pada delay antara $0.034897000 \mathrm{~s}-0.037563000 \mathrm{~s}$ selama live streaming berlangsung. Berdasarkan penelitian ini dapat diambil kesimpulan bahwa kipas dapat menyala secara otomatis dan berhasil menurunkan suhu tubuh pada pengguna secara bertahap dengan rentang suhu antara $35.00^{\circ} \mathrm{C}-36.8^{0} \mathrm{C}$.

Kata kunci-Suhu tubuh, denyut jantung, android,thermal infrared non - contact.

\section{PENDAHULUAN}

Kesehatan merupakan bagian terpenting dalam segala aktivitas yang dilakukan oleh manusia. Untuk itu perlu dilakukannya monitoring kesehatan secara rutin, agar dapat segera diambil tindakan ketika tanda-tanda kesehatan menunjukan adanya penurunan. Tanda-tanda vital kesehatan manusia dapat diketahui dari bebarapa macam seperti suhu tubuh, denyut nadi, pernasapan, dan tekanan darah. Dari tanda-tanda vital tersebut, suhu tubuh merupakan salah satu tanda yang perlu diperhatikan. Suhu tubuh dapat diukur pada sublingual (di bawah lidah), rektal (dubur), dan aksila (ketiak) [1].

Suhu tubuh manusia sangat mudah sekali berubah dan dipengaruhi oleh banyak faktor, baik faktor eksternal maupun faktor internal [2]. Salah satu factor eksternal ialah suhu lingkungan dimana berkisar antara $20^{\circ} \mathrm{C}-23^{\circ} \mathrm{C}$ merupakan suhu yang optimal terhadap VO2Max (pengambilan oksigen) dan kadar asam laktat dalam darah pada saat jeda istirahat serta pada saat aktifitas. Proses peningkatan suhu lingkungan, kelembaban udara dan suhu tubuh, sangat berpengaruh terhadap tingkat dehidrasi tubuh. Proses dehydrasi, kecepatan aliran darah, dan sekresi keringat semakin meningkat pula sesuai dengan peningkatan suhu tubuh sebagai bentuk peningkatan metabolisme dan perubahan energi, serta sebagai bentuk proses penekanan terhadap suhu tubuh yang tinggi. Jika hal tersebut dibiarkan dalam jangka waktu yang lama, tubuh bisa mengalami dehidrasi, heat exhaustion, heat stroke, heat asthenia, dan bahkan terburuknya adalah serangan jantung [1]. Di dalam tubuh energi panas dihasilkan oleh jaringan aktif terutama 
dalam otot, kemudian juga dalam alat keringat, lemak, tulang, jaringan ikat, serta saraf. Energi panas yang dihasilkan didistribusikan ke seluruh tubuh melalui sirkulasi darah, namun suhu bagian-bagian tubuh tidak merata. Perubahan produksi energi panas akan sangat besar dan cepat akibat latihan fisik yang berlebihan [3].

Latihan fisik merupakan aktivitas yang dilakukan dan merupakan akibat dari kontraksi otot dengan melibatkan sistem ketahanan untuk menjalankan kegiatan sehari-hari. Litihan fisik ini menyebabkan suatu perubahan yang terjadi pada tubuh manusia, baik secara akut maupun secara kronis. Latihan fisik secara teratur dalam waktu cukup lama yaitu kurang lebih 30 menit dapat menyebabkan perubahan terhadap fungsi tubuh yaitu tekanan darah dan frekuensi denyut nadi istirahat. Efek akut dari latihan fisik adalah peningkatan terhadap tekanan darah, frekuensi pernapasan, frekuensi denyut jantung, dan suhu tubuh, Latihan fisik dengan intensitas berat selama 20 menit akan meningkatkan suhu tubuh dari $37^{\circ} \mathrm{C}$ menjadi $40^{\circ} \mathrm{C}[4]$.

Berdasarkan paparan latar belakang tersebut, Penelitian ini dilakukan bertujuan memonitoring suhu tubuh manusia saat berolahraga dengan kadar asam yang dikeluarkan oleh keringat melalui pori-pori kulit. Melalui sistem Mikrokontroler Berbasis Android yang nantinya akan diaplikasikan pada Jaket. Jaket ini nantinya akan terhubung pada Android yang digunakan untuk memonitoring serta mengatur suhu pada jaket yang telah tersambung dengan mikrokontroler dibantu database utama dan smartphone sebagai pendeteksi suhu yang dibutuhkan setiap kali pengguna menggunakan jaket tersebut.

\section{METODE}

Penelitian ini dilakukan di Politeknik Negeri Malang Program Studi Jaringan Telekomunikasi Digital pada Juli 2020 yang digunakan untuk mengetahui permasalahan yang sedang dilakukan, yaitu tentang peran pemanfaatan sensor suhu dengan tambahan sensor pendukung lainnya pada jaket. Peran tersebut antara lain mekanisme kipas berdasarkan deteksi keluaran dari sensor suhu pada jaket, sehingga penelitian ini termasuk dalam research and development yaitu membangun suatu sistem yang diaplikasikan pada alat-alat kesehatan.

\section{A. Tahapan Penelitian}

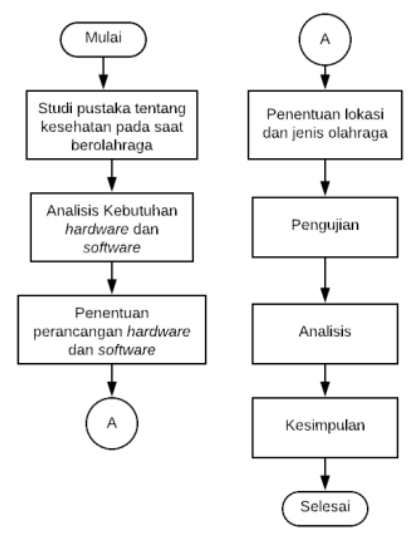

Figure 1. Diagram Alir Tahapan Penelitian

B. Blok Diagram Perangkat

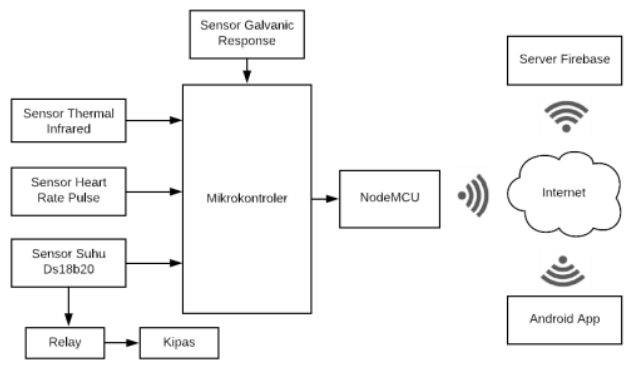

Figure 2. Blok Diagram Perancangan Sistem Penelitian

C. Blok Input

Pada blok input terdiri atas beberapa macam sensor yang memiliki fungsi sebagai berikut:

1. Modul Sensor GSR

Modul sensor GSR berfungsi sebagai pendeteksi kelembaban kulit berdasarkan keringat yang dihasilkan pada saat pengguna melakuka aktifitas olaharaga.

2. Sensor Suhu

Sensor suhu DS18B20 berfungsi sebagai pembaca nilai suhu tubuh pengguna sepeda statis yang mana datanya akan diolah di arduino uno sebagai salah satu parameter untuk monitoring suhu .

3. Sensor Detak Jantung

Sensor detak jantung atau Heart rate pulse sensor berfungsi sebagai pembaca nilai detak jantung saat bersepeda, yang mana data yang didapatkan akan diolah pada arduino uno sebagai salah satu parameter detak jantung.

4. Sensor Thermal Infrared

Sensor thermal infrared ini digunakan untuk mengetahui kualitas pengguna sebelum melakukan kegiatan olahraga. Disamping untuk kesehatan, sensor ini juga bisa digunakan sebagai pendeteksi suhu tubuh.

\section{Blok Kontrol}

Pada blok proses terdiri atas sebuah mikrokontroler Arduino Uno yang berfungsi untuk memproses dan 
mengolah data masukan dari sensor pada blok input sehingga dapat diteruskan pada blok output.

\section{E. Blok Output}

Pada blok output terdiri dari komponen yang mendukung untuk menampilkan data hasil pembacaan sensor pada aplikasi android yang terhubung oleh internet.

1. NodeMCU

NodeMCU berfungsi sebagai perangkat transmisi data hasil dari pengolahan arduino uno yang dilakukan secara wireless antara perangkat sistem dengan android menggunakan bantuan firebase sebagai database atau penyimpanan data oleh sensor.

2. Android

Android berperan sebagai perangkat yang digunakan untuk menampilkan data dalam bentuk text maupun grafik yang telah diolah dari blok input dan blok proses.

\section{F. Diagram Sistem Keseeluruhan}

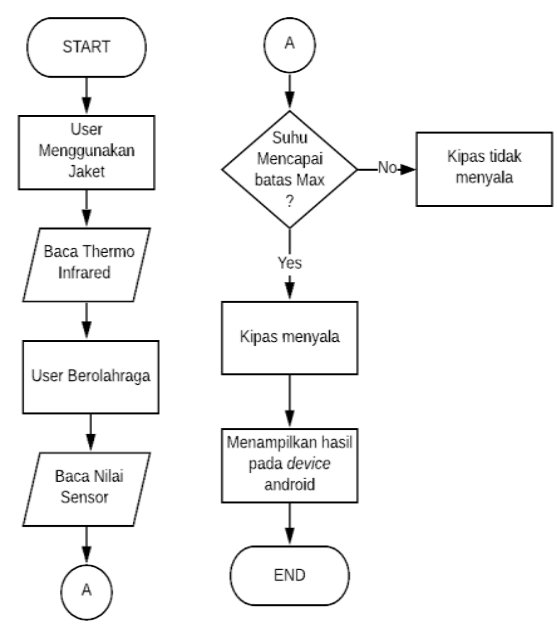

Figure 3. Diagram Alir Sistem

Pada Gambar 3 saat perangkat sudah terkoneksi dengan jaringan Wifi dan pengguna sudah melakukan pembacaan suhu dengan sensor thermal, dan mulai berolahraga, sensor denyut jantung mulai bekerja mengambil jumlah denyut jantung yang terdeteksi. Jika terdeteksi adanya denyut jantung maka sensor gsr dan sensor suhu DS18B20 mulai mengambil data yang langsung dikirimkan kepada server firebase dan selanjutnya akan ditampilkan pada aplikasi android. Jika suhu terdeteksi melebihi suhu maksimal (rentang suhu $35.0^{\circ} \mathrm{C}-36.8^{\circ} \mathrm{C}$ ) maka kipas akan menyala secara otomatis guna menurunkan suhu tubuh.

\section{G. Diagram Alir Aplikasi Android}

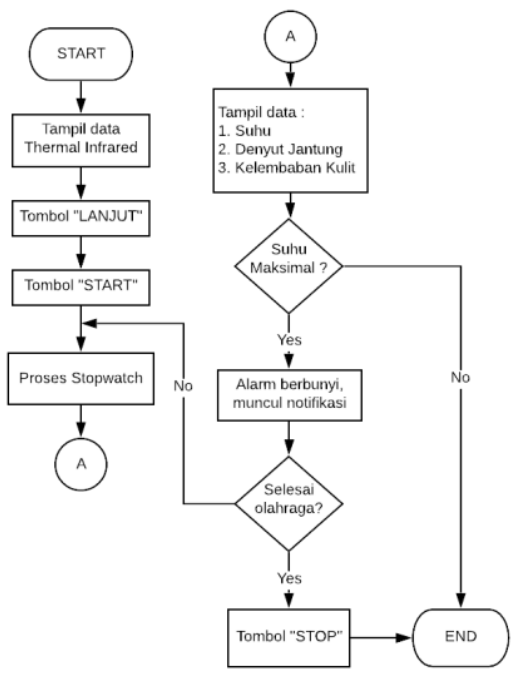

Figure 4. Diagram Alir Aplikasi Android

Pada Gambar 4 menjelaskan tentang flowchart aplikasi android, pertama-tama user yang akan melakukan pengecekan suhu menggunakan sensor thermal non contact sebelum melakukan olahraga, setelahnya menekan tombol lanjut untuk berlaih pada halaman selanjutnya dengan tombol start atau mulai, yang menandakan mulainya kegiatan olahraga dilakukan. Setelah menekan tombol start, maka beralih kepada proses stopwatch dimana waktu akan terus berjalan selama yang diinginkan, dengan secara otomatis data suhu tubuh, denyut jantung, dan kelembaban kulit yang didapatkan oleh sensor akan ditampilakn melalui aplikasi. Jika terdeteksi suhu mencapai batas maksimal yang sudah ditentukan, maka alarm akan berbunyi yang menandakan bahwa suhu tubuh pengguna sedang dalam keadaan panas, serta notifikasi yang terdapat pada aplikasi berguna sebagai pertanda bahwa suhu mencapai maksimal. Jika pengguna ingin menyudahi kegiatan berolahraga, maka dapat menekan tombol stop atau berhenti.

\section{HASIL DAN PEMBAHASAN}

\section{A. Hasil Penelitian}

Hasil Pengujian Alat, Sstem, Aplikasi

TABLE 1

Hasil Pengujian Alat Sebelum Olahraga

\begin{tabular}{c|c|c|c|c|c|c}
\multicolumn{6}{c}{ HASIL PENGUJIAN ALAT SEBELUM OLAHRAGA } \\
\hline $\begin{array}{c}\mathrm{N} \\
\mathrm{o}\end{array}$ & Umur & $\begin{array}{c}\text { Jenis } \\
\text { Kela } \\
\mathrm{min}\end{array}$ & $\begin{array}{c}\text { Infrare } \\
\mathrm{d}\left({ }^{\circ} \mathrm{C}\right)\end{array}$ & $\begin{array}{c}\text { Suhu } \\
\left({ }^{\circ} \mathrm{C}\right)\end{array}$ & $\begin{array}{c}\text { Kelem } \\
\text { bapan } \\
\text { Kulit } \\
(\%)\end{array}$ & $\begin{array}{c}\text { Denyut } \\
\text { Jantun } \\
\mathrm{g} \\
(\mathrm{bpm})\end{array}$ \\
\hline 1 & 23 & $\mathrm{P}$ & 35 & 35.88 & 47 & 99 \\
\hline 2 & 20 & $\mathrm{~L}$ & 36.09 & 36.19 & 47 & 18 \\
\hline 3 & 22 & $\mathrm{P}$ & 35.99 & 36 & 47 & 95 \\
\hline 4 & 14 & $\mathrm{~L}$ & 35.23 & 35.06 & 47 & 94 \\
\hline 5 & 22 & $\mathrm{P}$ & 34.55 & 35.44 & 47 & 97 \\
\hline 6 & 18 & $\mathrm{~L}$ & 35.19 & 36.13 & 47 & 107 \\
\hline
\end{tabular}


TABLE 2

PENGUJian Alat SElama Olaharaga

\begin{tabular}{c|c|c|c|c|c}
\hline No & Umur & $\begin{array}{c}\text { Jenis } \\
\text { Kela } \\
\text { min }\end{array}$ & $\begin{array}{c}\text { Suhu } \\
\left({ }^{\circ} \mathrm{C}\right)\end{array}$ & $\begin{array}{c}\text { Kelemba } \\
\text { pan Kulit } \\
(\%)\end{array}$ & $\begin{array}{c}\text { Denyut } \\
\text { Jantung } \\
(\mathrm{bpm})\end{array}$ \\
\hline 1 & 23 & $\mathrm{P}$ & $\begin{array}{c}36.4 \\
4\end{array}$ & 47 & 95 \\
\hline 2 & 20 & $\mathrm{~L}$ & $\begin{array}{c}36.7 \\
5\end{array}$ & 47 & 96 \\
\hline 3 & 22 & $\mathrm{P}$ & $\begin{array}{c}36.7 \\
5\end{array}$ & 47 & 95 \\
\hline 4 & 14 & $\mathrm{~L}$ & $\begin{array}{c}36.6 \\
9\end{array}$ & 47 & 94 \\
\hline 5 & 22 & $\mathrm{P}$ & $\begin{array}{c}36.3 \\
8\end{array}$ & 47 & 101 \\
\hline 6 & 18 & $\mathrm{~L}$ & $\begin{array}{c}36.8 \\
1\end{array}$ & 47 & 105 \\
\hline
\end{tabular}

\section{B. Pembahasan}

Setelah dilakukannya berbagai uji coba dari uji coba keseluruhan pada sistem, aplikasi, maupun alat yang didapatkan adalah hasil yang sesuai dengan perencanaan yang dibuat sebelumnya. Sebagai produk yang telah teruji, sistem ini dapat dikatan sudah memenuhi tujuan, yaitu mampu mengontrol suhu yang diperlukan berdasarkan keringa yang dihasilkan melalui Android pada jaket. Data dari setiap sensor yang digunakan akan disimpan secara realitime di database, kemudian akan tersimpan di dalam aplikasi sebagai bentuk laporan hasil data selama penggunan jaket tersebut. Smartphone yang digunakan dan sudah terpasang aplikasi android, maka mampu menampilkan hasil data yang diperoleh tiap sensor dalam bentuk grafik.

Tingkat usia dan juga jenis kelamin dalam olahraga sangat berpengaruh pada hasil denyut jantung, suhu tubuh, dan kelembaban kulit. Namun, salah satu faktor pada kelembaban kulit juga dipengaruhi oleh tingkat keringat yang dihasilkan saat berolahraga, yang artinya tingkat keringat itu sendiri dihasilkan oleh banyaknya kadar air yang terdapat dalam tubuh manusia. Berdasarkan tabel 1 dan tabel 2 hasil pengujian alat, dapat dilihat bahwa terdapat data yang signifikan pada data yang diambil ketika sebelum dilakukannya olahraga dengan data yang diambil selama olahraga berlangsung.

Berdasarkan tabel 1 yaitu data yang diambil sebelum olahraga memiliki nilai pada suhu infrared berkisar $34.55^{\circ} \mathrm{C}$ - 36.09 $\mathrm{C}$, suhu tubuh antara $35.06^{\circ} \mathrm{C}-36.19^{\circ} \mathrm{C}$, serta kelembaban kulit dan juga denyut jantung bernilai antara $47 \%$ dan 94Bpm - 118 Bpm. Sedangkan berdasarkan tabel 2 yaitu data yang diambil selama olahraga berlangsung mendapatkan nilai pada suhu tubuh antara $36.38^{\circ} \mathrm{C}-$ $36.81^{\circ} \mathrm{C}$, nilai pada kelembaban kulit antara $47 \%-15 \%$, dan denyut jantung antara $105 \mathrm{Bpm}-94 \mathrm{Bpm}$. Pada saat suhu tubuh mendapatkan nilai diatas $36.8^{\circ} \mathrm{C}$ maka kipas yang sudah terpasang pada jaket akan menyala secara otomatis. Begitu juga dengan kelembaban kulit, pada saat melakukan pengujian alat dan sistem diketahui bahwa semakin besar nilai yang diperoleh pada kelembaban kulit, maka semakin kecil keringat yang terdeteksi, yang artinya pada saat berolahraga keringat yang dihasilkan oleh pengguna hanya sedikit.
Hal ini menunjukkan bahwa pada saat panas maka pembuluh darah di sekitar permukaan kulit akan melebar sehingga proses penyerapan dalam darah akan masuk ke dalam kelenjar keringat dan dikeluarkan ke luar tubuh melalui keringat, yang artinya pada saat suhu tubuh naik maka kelenjar keringat akan memproduksi keringat yang banyak, sehingga menyebabkan nilai pada kelembaban kulit mengecil. Sedangkan semakin suhu tubuh meningkat akan berbanding lurus dengan kerja denyut jantung. Jika suhu tubuh meningkat maka akan menyebabkan otak akan mengontrol keseimbangan tubuh agar tetap seimbang, karena jika terus terpapar oleh suhu tinggi tekanan denyut jantung akan mengalami heat stress atau kelelahan. Sistem yang bekerja pada kipas dapat berjalan dengan baik, pada saat suhu sudah mencapai $36.8^{0} \mathrm{C}$.

\section{KESIMPULAN}

1. Rentang suhu tubuh yang digunakan untuk mengatur keadaan kipas on/off sebesar $35.0^{\circ} \mathrm{C}-36.8^{\circ} \mathrm{C}$, maka pada saat pengguna sedang berolahraga dan mendapatkan suhu sebesar $36.8^{\circ} \mathrm{C}$ atau lebih, maka relay akan mengaktifkan kipas yang berfungsi menurunkan suhu secara perlahan.

2. Pada proses pengiriman data yang didapatkan selama live streaming berlangsung dengan nilai delay terendah sebesar 0,034897000 s sedangkan nilai delay terbesar sebesar $0,037563000 \mathrm{~s}$ dan tidak adanya packet loss selama pengiriman data.

\section{REFERENSI}

[1] S. F. Suyanto Moh Fajar Rajasa, "Rancang Bangun Prototipe Monitoring Suhu Tubuh Manusia Berbasis O.S Android Menggunakan Koneksi Bluetooth," J. Tek. ITS, vol. 2, no. Vol 2, No 1 (2013), pp. A213A216, 2013.

[2] M. Ramdhani and A. Rizal, "Rancang Bangun Termometer Digital Berbasis Sensor Ds18B20 Untuk Penyandang Tunanetra ( Design Digital Thermometer Based on Sensor Ds18B20 for Blind," vol. 4, no. 3, pp. 3294-3301, 2017.

[3] D. Aranda, "Bab Ii Dasar Teori 2.1 Nodemcu Esp8266," pp. 3-8, 2017.

[4] I. Sandi, I. Ariyasa, I. Teresna, and K. Ashadi, "Pengaruh Kelembaban Relatif Terhadap Perubahan Suhu Tubuh Latihan," Sport Fit. J., vol. 5, no. 1, pp. 103-109, 2017. 